IRA-International Journal of Management \& Social Sciences

ISSN 2455-2267; Vol.04, Issue 02 (2016)

Pg. no. 387-393

Institute of Research Advances

http://research-advances.org/index.php/RAJMSS

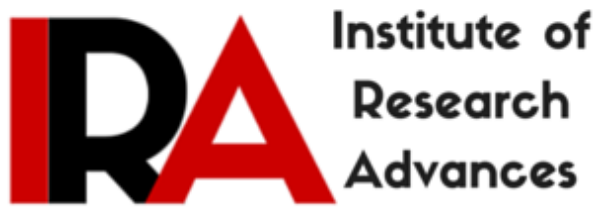

\title{
Socio- Religious Dichotomy among the Gujjars of Himachal Pradesh
}

\section{Dr. Bindu Sahni}

VPO Ambota, Tehsil Amb,

District Una (Himachal Pradesh), India.

Type of Review: Peer Reviewed.

DOI: http://dx.doi.org/10.21013/jmss.v4.n2.p8

\section{How to cite this paper:}

Sahni, B. (2016). Socio- Religious Dichotomy among the Gujjars of Himachal Pradesh. IRA-International Journal of Management \& Social Sciences (ISSN 2455-2267), 4(2), 387-393. doi:http://dx.doi.org/10.21013/jmss.v4.n2.p8

(C) Institute of Research Advances

\section{(c)) EY-NC}

This work is licensed under a Creative Commons Attribution-Non Commercial 4.0 International License subject to proper citation to the publication source of the work.

Disclaimer: The scholarly papers as reviewed and published by the Institute of Research Advances (IRA) are the views and opinions of their respective authors and are not the views or opinions of the IRA. The IRA disclaims of any harm or loss caused due to the published content to any party. 
The Gujjars are primarily a pastoral tribe. They possess huge herds of buffaloes and in search of better grazing grounds they are constantly on the move. In Himachal Pradesh Gujjars are bracketed as a Scheduled Tribe. As per the Census of 2011, 5.7\% population of Himachal Pradesh falls in the category of Scheduled Tribe. Though Gujjars are scattered all over Himachal Pradesh, their major concentrations are in Bilaspur, Chamba, Kangra and Una districts. Presently, Gujjars in Himachal Pradesh are nomad, semi-nomad and settled. Gujjars of Chamba and Kangra lead nomadic life, in Una and Bilaspur regions they are permanent settlers. Nomad Gujjars are those who keep on wandering from one place to another in search of grazing facilities. Nomad Gujjars always roam and shuttle between the higher and the lower hills in search of grazing tracts. Nomad Gujjars are known as Heer Gujjars in Una and Bilaspur and in Chamba and Kangra they are recognized as Ban Gujjars. The semi nomad Gujjars, though have permanent places of stay, they leave that for short periods in winters when the year faced scarcity of grazing grounds and return back in summers; after spending the winter in the rich grazing tracts; to their permanent residence in summers. Gujjars of Kangra lead a semi-nomadic life. Lyall mentions these seminomadic Gujjars of Kangra as Sawana Gujjars, who followed fixed grazing route i.e. in spite of being constantly on the move they follow the fixed tract every year and used to stay in the same huts where they stayed last year. ${ }^{1}$ Presently also these Gujjars are known as Sawana Gujjars. Settled Gujjars are those Gujjars who did not move any in search of grazing facilities, instead possess their own lands and grazing tracts and lead a settled life. These Gujjars have their permanent houses. Gujjars in Una and Bilaspur lead a settled life. Melveill, the first settlement officer of Una, confirms their settlements in Una as early as $1860 \mathrm{s.}^{2}$ However, in spite of leading diverse lifestyles one common thing between these nomad and settled Gujjars is that they all keep huge herds of buffaloes. Nomad (Ban) and semi nomad (Sawana) Gujjars in Himachal Pradesh are all Muslim by religion while settled Gujjars are largely Hindu; though a few among them are Muslim.

The process of Gujjar conversions into Islam appear to have began as early as eleventh century. Ganesh Das, writing in 1849, states that Hindu Gujjars of Lahore converted to Islam during the $11^{\text {th }}$ century under the influence of Sufi, Khawaja Ali Hujwiri popularly known as Data Ganj Bakhsh (1073 C.E.). ${ }^{3}$ Ibbetson informs us that a few Gujjars were converted to Islam during Aurangzeb's reign in Jalandhar district of the Undivided Punjab, "They are almost exclusively Musalman except in the Jamna districts and Hushyarpur, and they must therefore have entered those districts before the conversion of the great mass of the caste. The Jalandhar Gujars date their conversion from the time of Aurangzeb, a very probable date." Ibbetson further add that, "The Musalman Gujars of all the eastern half of the Province still retain more of their Hindu customs than do the majority of their converted neighbours." Gujjars are found mostly in the district of Mandi, Kangra, Sirmaur, Solan, and Bilaspur and Una, whereas Muslim Gujjars are dispersed in the districts of Chamba, Mandi, Solan, Sirmaur and Una. Major concentration of Hindu Gujjars is in Bilaspur and Una while Muslim Gujjars are in Kangra and Chamba.

The present study seeks to explore the Hindu and Muslim customs and traditions of the Gujjars of Himachal Pradesh and what is common among them. In this regard the present paper looks into the socioreligious dichotomy of the Hindu and Muslim Gujjars from three perspectives i) gotra and clan affiliation, ii) marriage customs iii) religious associations.

1 Lyall, J.B., Report of the Land Revenue Settlement of the Kangra District, Panjab, 1867-72, Lahore: Central Jail Press, 1874, p. 55 .

2 Melveill, P.S., Report of the Revised Settlement of the Oonah, Hushiarpur, Gurshunkur and Hurriana Purganahs of the Hushiarpur District, Lahor: Punjab Press, 1860, p. 4

${ }^{3}$ Das, Ganesh, Char Bagh-i Panjab, translated by J.S Grewal and Indu Banga, Early Nineteenth Century Panjab, Amritsar: Guru Nanak University, 1975, p. 118.

Ibbetson, Denzil, Panjab Castes, Delhi: Low Price Publication, 1993 [1916], p. 183.

5 Ibid, pp. 183-84. 


\section{i) Gotra and Clan Affiliations}

All Gujjars irrespective of their religious affiliations (Hindu or Muslim) possess more or less similar gotras, which is indicative of the fact that they all share were one ancestry. The Gujjars usually move in groups and that group is based on the clan/gotra. Usually Gujjars of the same clan/gotra live together. These clans thus give a unique identification to the Gujjars. William Crooke (1896) mentions that, "Like many castes which have a preference for seven or one of its multiples, the Gujars pretend to have eighty-four exogamous gotras or section. ${ }^{6}$ Crooke further adds and mentions some names of the major clans of Gujjars:

Of these those locally of most important are the Batar, Buchar, Chhotkana, Hamar, Kanas, Khatana, Khubar, Rathe, and Rawal, in Saharnpur: the Kalsiyan and Khubar, of Muzaffarnagar, the Adhana, Bhatti, Chandela, Dhandhal, Hels, Kasana, Khare, Khubar, Marsi, and Nagari, of Meerut : the adhana, Bhadana, Bhatti, Kasana, and Nagari, of Buladshahr : the Tomar, of Mathura: the Dalel and Pomar, of Agra : the Lohar, of Jalaun. ${ }^{7}$

Crooke states that they adopt these gotras after the name of the villages or after the name of the head of the family. He mentions that, "It will be seen that the names differ almost all through the lists. Most of these names are said to be derived from the titles of tribal leaders or from the villagers in which their early settlement were found." "Ibbetson mentions only nineteen gotras or clans of Gujjars to which he identifies as tribes of Gujjars as against 84 of Crook, he comments that, "The Gujjar tribes and clans appear to be very numerous, and apparently new local sub-divisions have sprung up in many places."9 The name of the clans which were recorded by Ibbetson are - Tanwar, Chokhar, Rawal, Kalsian, Kathana, Kasanab, Kalas, Gorsi, Chechi, Dhodar, Poswal, Lawi, Bijar, Khaindar, Melu, Thakaria, Chauhan, Monana, and Bhumls. ${ }^{10}$ Ibbetson further elaborates that large chunk belonged to, "the Kathana and Chechi far surpass the others in number." Out of these gotra Bhathis, Tomors, Chauhan overlap with the similar Rajput and Jat lineages. H.A Rose, however, in contrast finds Kasana and Gorsi as the main gotras of the Gujjars.

He comments that:

It is generally asserted that real (asli) or original Gujars are the two and half sections, Gorsi, Kasana and the half tribe Burgat, so called as descended from a slave mother. Next to these rank the Khatanas who for a long period held sway in the Gujrat in which tract, however, the two and half section were the original settlers, the other section having become affiliated to them in course of time, though not necessarily Gujars by origin. The Gujars are often said to have 84 clans or section and in Ludhiana their Mirasis address them as 'Chaurasi got da diwa' i.e 'Light of the 84 clans'; but other accounts assign them 101,170 or even 383 sections. ${ }^{12}$

\footnotetext{
${ }^{6}$ Crooke William, The Tribes and Castes of the North-Western Provinces and Oudh, Vol. II, Calcutta: Office of the Superintendent of Government Printing, 1896, p. Crooke, 1896, p. 443.

7 Ibid.

${ }^{8}$ Ibid.

9 Ibbetson, 1916, p. 188.

10 Ibid.

11 Ibid.

12 Rose, 1990 [1916], pp. 314-15.
} 
P.L.Fagan (1904), while explaining the Gujjars of Hoshiarpur district mentions Dhai, Kasana, Gursi and Barkat, Chechi, Bhumbhhe, Bajar and Chauhan gotras of Gujjars. ${ }^{13}$ He writes that, "There is a dhai got of Gujars, Kasana, Gursi and Barkat. Other Chief gots in this District are Chechi, Bhumbhe, bajar, and Chauhan. They are said to be all $84 ., 14$

The gotras of Gujjars found in Himachal Pradesh are Khatana, Chauhan, Gursi, Didhar, Bhumphal, Katariya, Parswal, Malehria, Koli, Chechi, Bhunch, Badlas, Kalas, Chhore, Ladhi, Chai, Bajar and Badhena. Bhatti, Chandel, Kasana, Bhensi, Chopra, Chechi, Khatana, Nand. ${ }^{15}$ There is diversity among the gotras of Gujjars. In sajra nasibs clan wise descriptions of the Gujjars, who are prime settler of the villages of Bilaspur have been given. Nomad and semi nomad Gujjars have their own gotras. The main gotras among nomad gujjars are Chauhan, Bajaj, Chechi, Jinjer, Kararay, Dikri, Lodhi and Gorsi. Their clan identity is required to distinct them from one another.

Gotras among the Gujjars of Himachal Pradesh

\begin{tabular}{|c|c|c|c|}
\hline \multicolumn{3}{|l|}{ SETTLED GUJJARS } & NOMAD GUJJARS \\
\hline $\begin{array}{l}\text { Gotras of Hindu } \\
\text { settled Gujjars of } \\
\text { Bilaspur as per Sajra } \\
\text { Nasibs }\end{array}$ & \begin{tabular}{llr} 
Settled & \multicolumn{2}{r}{ Hindu } \\
Gujjars & \multicolumn{2}{c}{ clans in } \\
villages & of & $\begin{array}{r}\text { Una } \\
\text { Uistrict }\end{array}$ \\
(field \\
survey)
\end{tabular} & $\begin{array}{l}\text { Settled Muslim Gujjars } \\
\text { clans of Kangra and } \\
\text { Una district (field } \\
\text { survey) }\end{array}$ & $\begin{array}{ll}\text { Clan of } & \text { Nomad } \\
\text { (Ban/Heer) } & \text { Gujjars } \\
\text { (Muslim) } & \end{array}$ \\
\hline Janer & Kasana & Bhatti & Chauhan \\
\hline Haner & Khepar & Chandel & Banaj \\
\hline Gorsi & Kataria & Chauhan & Chechi \\
\hline Mainden & Jingar & Bhunch & Jinjer \\
\hline Fulu & Bajad & Lodhi & Kararay \\
\hline Mahnga & Chauhan & Kasana & Dhikri \\
\hline Chauhan & Bhumphal & Bhensi, & Lodhi \\
\hline Kewari & Katariya & Chopra & Gorsi \\
\hline Ladhi & Chechi & Chechi, & Badlas \\
\hline Kasath & Bhumeley & Khatana & Talaney \\
\hline Kharu & Hans & Parswal & Koli \\
\hline Kasar & Bagri & Didhar & Malehria \\
\hline Khager & Khatana & Gani & \\
\hline Takar & Nand & Gorsi & \\
\hline Chechi & Beetan & Bazarder & \\
\hline
\end{tabular}

Source: (i) Sajra Nasib, Mauza Palsid, Bassi, Bilaspur, Naina Devi, Pargana Kot Khalour, Tehsil Bilaspur, 1908, Record office of Deputy Commissioner, Bilaspur.

(ii) Field survey to Nomad Gujjars along the khads of Una district dt $21^{\text {st }}$ October, 2013.

\footnotetext{
${ }^{13}$ Fagan, P.L., Punjab District Gazetteer, Vol. XIII A, Hoshiarpur District (1904), Lahore: Punjab Government Press, 1905, p. 57.

14 Ibid.

${ }^{15}$ Field Survey, Village Sagnia, Village Ganari, Village Deoli, Tehsil Amb, District Una, 4october, 2012, village Kahlour, Village Bassi, Tehsil Shri Naina Devi, District Bilaspur, 8 July, 2013.
} 
Among the gotras of the Gujjars elaborated in the sajra nasibs three main gotras are chechi, Chauhan, Gorsi are also found in the clans elaborated by the Ibbetson, however the names of gotras Janer, Haner, Mainden, Kewari, Kharu, Kasar, Khager, Takar are neither elaborated by Crooke and Ibbetson nor by Rose. In the villages of Bilaspur major concentration is of the Gujjars of Chechi and Chanhan gotras. Chauhan and Chechi gotras of Gujjars are denoted in Hindu and Muslim settled Gujjars even in nomad they are found. Gujjars of kasana gotra are all settled. The clans of nomad Gujjars; chauhan, Gorsi, chechi, and Lodhi are also found in settled Gujjars, however clans Banaj, Jinjer, Dhikri, Badlas, Talaney are all nomad in Himachal Pradesh. Thus despite of their diversity of nomad and settled they have same clans.

\section{ii) Marriage customs}

These gotras denote their ancestry and regulate marriage alliance. ${ }^{16}$ Fagan records that Gujjars marry within their own gotras which is quite contradictory, as in my field survey I was informed by the Gujjars that they would not marry in their own gotras. Fagan writes that, "there is no restriction of marriage within these gots, a Gujar can marry within own got or in any other." 17

Inspite of having the similarity of gotras in Hindu as well as Muslim Gujjars, their religious believes and rituals are all different from each other. Settled Gujjars considered themselves more superior as compare to their nomad counterparts. Even settled Gujjars avoid the marriage relations with the nomad Gujjars. However in special circumstances settled Gujjars like to take the daughter of nomad gujjars for their son but did not allow marrying their daughters to the nomad Gujjars. The settled Gujjars looked down upon nomad Gujjars and keep distance from them. Karim Baksh (Settled Gujjar) informed me that Gujjars though take the girl from nomad Gujjars they do not allow their daughters to marry nomad Gujjar. ${ }^{18}$ The nomad Gujjars performed marriage from one tribe to other, as the tribes are based on the clan identity.

Hindu Gujjars performed all rituals according to the Hindu customs. The prohit of each Hindu Gujjar clan wise are different. Prohit of Hindu lives in the other village and generally used to come to attend the functions. ${ }^{19}$ Marriages are performed according to the Hindu rituals. But one unique thing among Hindu Gujjars is that they used to sing the marriage songs together means one line of the song is sung by the women and the other line by the men. These songs are all in gujari language. After the marriage of the son Dham (village feast) is performed and all villagers are invited on this occasion to eat the meal. At the time of marriage of daughter special respect is given to the marriage party (Barat) of the boy. And it was informed to me that it was custom to distribute the ghee to all the members of the marriage party. Shagun was sent to the boy's house. Dowry is not found in Hindu Gujjars however they used to give buffaloes.

The marriage rituals are different of nomad Gujjars from the settled Gujjars. However maulavis is the prime need of the marriages among both nomad and settled Muslim Gujjars. But their rituals are quite different from each other. This may also due to the reason that due to the assimilation of the Muslim settled Gujjars with the local community and on the other hand nomad Gujjars live isolated life which is quite different from settled Gujjars. One common thing among them is that they never married among their own gotras. Gotras are firstly important aspect to settlement of a marriage relation. Marriage can only take place among two different gotras. The batta satta marriages are very common among the settled Muslim Gujjars, in which if they took the girl for their son they will also marry their daughter in that family.

\footnotetext{
${ }^{16}$ Personal interview with Joginder Singh; Settled Gujjar of Village Gol Jawal, Tehsil Naina Devi, District Bilaspur, 14 April, 2011.

${ }^{17}$ Fagan, 1904, p. 57.

18 Personal interview with Karim Baksh, a settled Gujjar, Village Bera, District Una on $19^{\text {th }}$ March, 2013.

19 Personal interview with Ved Parkash, Prohit of Chauhan Gujjar, in Village Dulehta, Tehsil Gumaravi, District Bilaspur, 8 April, 2011.
} 
Among the Muslim Gujjars one special custom performed at the time of the marriage is Lassi Chilaye. When a new bride comes to her in-laws, the very first function is the ritual to make buttermilk. During the ritual each family member put some rupees in her lap as a good omen. However in nomad Muslim Gujjars when bride came to the Dera of her in-laws, her mother in- law firstly prepare food for her and give it to her daughter in-law. The nomad Muslim Gujjars performed marriage from one tribe to other. Some time they marry their daughters among the settled Gujjars also. Kantha, the only ornament which is worn by the women of Nomad Muslim Gujjars must be given to her by in-laws during marriage. Even dowry is also given to the daughter, but it is according to their financial position. Shagun and Dham (feast to all village communities) are essential in settled Muslim Gujjars and they invites all communities of the villages in these functions. However Nomad Gujjars did not have any such type of function. They only invite the Gujjars of another Deras (from another gotras or from the same gotras) who used to travel with them. There is a tradition among the nomad Gujjars that they participated in marriage ceremonies of other tribes (clan wise) with the ghee as per availability. In settled Gujjars there is no such type of custom. But both these settled and nomad Gujjars used to sing their folk lore in their own language that is gujri in the auspicious occasions of marriage and religious rituals. With passing of the time now they preferred to sing the popular latest songs in trend as compared to their folk lore. Nomad Gujjars however still sing their songs but they also denied singing them frequently due to the impact of modernization. ${ }^{20}$

Their dress also give them a distinguish look. Ibbetson argued by comparing the dress of the Muslim Gujjars women, who still used to wear Hindu Gujjars dress, that inspite of adopting the Muslim religion the Gujjar women still used to wear the Hindu women dress. Ibbetson further comments that, "The Musalman Gujars of all the eastern half of the Province still retain more of their Hindu customs than do the majority of their converted neighbours, their women for instance, wearing petticoats instead of drawers, and red instead of blue." ${ }^{21}$ Settled Gujjars used to wear modern dresses. But at the time of marriages the girls used to wear salwar kameez in both Hindu and Muslim communities. In nomad Gujjars the dressing style is quite different they used to wear salwar and usually both male and female keep a piece of cloth on their head. The male Gujjars wear a Kashmiri type of shirt and Punjabi type tamba. Men also have a shawl known as chadri with them. Women wear a chunni with their salwar kameez. They use silver ornaments also, which include necklace and kangan etc. They also wear large rings in the ears tied to long chains dangling down their shoulders. Nomad Gujjars women are perfect in stitching and usually stitch their clothes in their deras. Settled Gujjars have left to wear the traditional dress.

\section{Religious associations:}

Their religious believes are also different from one another. Hindus preferred to worship lord Krishna however Muslims are in the influence of Islam. Hindu Gujjars considered themselves as the offshoots of Lord Krishana. They have cows in their cattle and worship cows according to Hindu custom. Sh. Tarsem Chand a settled Hindu Gujjar who is a retired military person and now a member of Gujjars Kalyan Board has said that they are basically Hindu Gujjars, but some traditions of their family are performed according to the Gurdwara of Bhai Gurdita at Kirtpur Sahib (in modern Punjab). It may be possible that their ancestors have served their services to Bhai Gurdita and they become His followers. He also mentioned that every year they have to visit the holy Gurdwara at Kiratpur Sahib, Grave of Baba Budard Shah is also established there and simultaneously they visit the both spiritual places. The Dargah of Baba Budard Shah is very near to the Gurdwara of Bhai Gurdita. Sh. Tarsem Lal also said that they have some weapons of Sikh Gurus which are considered as their family property and they worship those weapons in every family ritual. Thus Gujjars have adopted some customs under the influence of Sikhism. Hindu Gujjars of Bilaspur also used to worship Lakh Data Pir, and a Merry bes (a separate buffalo) is used to

\footnotetext{
20 Personal interview with Nomad Gujjar, Nerudin, Karlui Khad, village Andora, District Una, 12 January, 2013.

21 Ibid, pp. 183-84.
} 
keep among the other buffaloes of these Gujjars whose milk is only used for the family and they never sell the milk of that buffalo. ${ }^{22}$ Such type of custom is not prevalent among the Muslim Gujjars. All Hindu Gujjars in Himachal Pradesh have their family deities known as dehrian and jatherian.

Settled Muslim Gujjars inspite to worshipping the Allah, also have their clan wise dehrian and jatherian (clan deity). In Gujjar villages different dehrian of different gotras can easily be found. Dehrian are the female deity of the clan and on the other hand jatherian are the male head of the family. Dehrian are not only common among Hindu Gujjars but even Muslim Gujjars also have their specific dehrians. In my field survey in a Muslim prominent village Dhar Gujran Di, when I inquired about their religion, their maulavi (religious priest) replied that they only worship Allah. But all the Gujjars who were present at that time accepted that they all have their family deities just at the outskirts of the village. They go to the dehrians on the occasion of marriages or on the birth of a male child. ${ }^{23}$ My survey suggests that these dehrians are generally clan based. Each clan group has a separate dehrian.

They worship these deities once in a year or even at the auspicious time of marriage of son or at the birth of the son. However nomad Gujjars did not have any such clan wise deity. They agreed that they worshipped some pir and used to visit at their dargah once in a year. Among their spiritual pirs, they visited the Pir Nigah at Una and dargah of Baba Ali Khan at Garshanker, which is the famous dargah of the area. As such these nomad Gujjars only follow the Muslim customs and nearby dargahs are their religious places to visit.

Thus inspite of their diversity of social and religious believes Gujjars have unified in one category. Hindu Gujjars are quite different from Muslim Gujjars and on the other hand Muslim nomad Gujjars have their own unique customs. Inspite of this disparity they all are one in using their language and their some auspicious rituals in which singing folk lore in their language is one. However assimilation in the local society is clearly reveals from their marriage and religious customs. They all used to have a large herds of buffaloes however Hindu Gujjars have cows among their cattle.

22 Personal interview with Sh Joginder Singh Chauhan, a prominent leader of Bilaspur.

23 Field Survey, village Dhar Gujjaran Di, Amb tehsil, Una district, 24 November 2012. 